\title{
Population awareness of coronary artery disease risk factors in Jeddah, Saudi Arabia: a cross-sectional study [Letter]
}

This article was published in the following Dove Press journal: International Journal of General Medicine

\author{
Anusha Sreejith' \\ Aji Gopakumar ${ }^{2}$ \\ Shatha Al Sharbatti ${ }^{1}$ \\ Jayadevan Sreedharan' \\ 'Department of Community Medicine, \\ College of Medicine, Gulf Medical \\ University, Ajman, United Arab Emirates; \\ ${ }^{2}$ Institutional Research Unit, Gulf Medical \\ University, Ajman, United Arab Emirates
}

Correspondence: Jayadevan Sreedharan Department of Community Medicine, College of Medicine, Gulf Medical University (GMU), P O Box 4I84, Ajman, United Arab Emirates

Email drjayadevans@gmail.com

\section{Dear editor}

The study titled "Population awareness of coronary artery disease risk factors in Jeddah, Saudi Arabia: a cross-sectional study" by Almalki et $\mathrm{al}^{1}$ is of much significance, due to the high prevalence of the disease in the region. The objective was to assess public awareness of risk factors for coronary artery disease. The authors did an extensive literature search on the prevalence and risk factors of the disease. As the study tackles a major population health problem, we hope the authors will clarify the following points.

No information about the justification of the sample size was included in the study. Inappropriate sample size may affect generalization of the results. ${ }^{2}$ The authors mentioned that the questionnaire was not validated, but the validity of the tool is very much important in this type of study.

The operational definition given for physical activity is "at least 3 minutes' walking 5 times a day", but 15 minutes/day is appropriate only for vigorous activity, as per the World Health Organization. ${ }^{3}$

It is more appropriate to compare median rather than the mean awareness scores (Table 2. Means and SDs are not appropriate statistics for variables with yes/no categories. Also, a normality test is inappropriate for such variables.

The authors repeatedly mentioned in the abstract, results, and discussion that the overall awareness scores for participants were significantly positively correlated with awareness of each risk factor. However, awareness score for each risk factor is a component of "total awareness score". One of the main assumptions of correlation is that variables should be independent, and hence the correlation coefficient calculated is not appropriate. ${ }^{4}$

An independent-sample $t$-test is used to compare mean awareness scores in Table 4, which is not an appropriate test for data that are not normally distributed. The comparison of mean/median scores is to check whether differences observed are statistically significant or not, not to find the correlation. Mean test results are wrongly interpreted as "significant correlation" in Table 4. The authors' misinterpretation in the second-last paragraph of the discussion ( $\mathrm{p}$ 67, lines 3-7) may lead to the wrong conclusion by the reader.

Table 2 shows that the dependent variable is mean awareness score and the independent variables are socio-demographic characteristics. Equal extent of grouping variable has no role on significance/non-significance of mean of the testing variable. Implies, 
absence of statistically significant differences in mean scores between the demographic characteristics not indicate equal extent of participant selection from different social, educational, and occupational classes of the population. At the end of the article many limitations were mentioned, those are necessarily to be followed while conducting any scientific research. $^{5}$

Overall, we appreciate the authors for their initiative. Inappropriate methodology, statistical method and interpretation of data may lead to fallacious conclusions.

\section{Disclosure}

The authors report no conflicts of interest in this communication.

\section{References}

1. Almalki MA, AlJishi MN, Khayat MA, et al. Population awareness of coronary artery disease risk factors in Jeddah, Saudi Arabia: a cross-sectional study. Int J Gen Med. 2019;12:63-70. doi:10.2147/ IJGM.S184732

2. Sathian B, Sreedharan J, Baboo SN, Sharan K, Abhilash ES, Rajesh E. Relevance of sample size determination in medical research. Nepal J Epidemiol. 2010;1(1):4-10. doi:10.3126/nje. v1i1.4100

3. World Health Organization (WHO). Global strategy on diet, physical activity and health. Available from: https://www.who.int/dietphysica lactivity/factsheet_adults/en/. Accessed April 5, 2019.

4. Schober P, Boer C, Schwarte LA. Correlation coefficients - appropriate use and interpretation. Anesth Analg. 2018;126(5):1763-1768. doi:10.1213/ANE.0000000000002864

5. Erol A. How to conduct scientific research? Noro Psikiyatr Ars. 2017;54(2):97-98. doi:10.5152/npa.2017.0120102

Dove Medical Press encourages responsible, free and frank academic debate. The content of the International Journal of General Medicine 'letters to the editor' section does not necessarily represent the views of Dove Medical Press, its officers, agents, employees, related entities or the International Journal of General Medicine editors. While all reasonable steps have been taken to confirm the content of each letter, Dove Medical Press accepts no liability in respect of the content of any letter, nor is it responsible for the content and accuracy of any letter to the editor.

\section{Publish your work in this journal}

The International Journal of General Medicine is an international, peer-reviewed open-access journal that focuses on general and internal medicine, pathogenesis, epidemiology, diagnosis, monitoring and treatment protocols. The journal is characterized by the rapid reporting of reviews, original research and clinical studies across all disease areas. The manuscript management system is completely online and includes a very quick and fair peer-review system, which is all easy to use. Visit http://www.dovepress.com/ testimonials.php to read real quotes from published authors. 